\title{
Knowledge Building Analytics to Explore Crossing Disciplinary and Grade-Level Boundaries
}

\author{
Ahmad Khanlari ${ }^{1}$, Gaoxia Zhu², and Marlene Scardamalia ${ }^{3}$
}

\begin{abstract}
Interdisciplinary studies foster integration of ideas across disciplines. The knowledge building pedagogy, with its 12 principles and associated technology, Knowledge Forum ${ }^{\circledR}$, provides multifaceted support for linking ideas across disciplines and communities. This exploratory study aims to assess the extent to which elementary-school students within knowledge building communities work productively with ideas across content areas. Toward that end we examine "crisscrossing topics" - student use of concepts from multiple content areas - to explore the extent to which students think and theorize across disciplinary boundaries, use concepts found in curriculum guidelines at and beyond their grade level, and generate cross-topic notes that advance discourse. Results show that elementary school students engaged in knowledge building can extend knowledge boundaries and bring a considerable range of conceptual content to their work, resulting in productive discourse threads that contribute to community knowledge.
\end{abstract}

\section{Notes for Practice}

- Knowledge building aims to recreate education as a knowledge creating enterprise; as such, explorations are not circumscribed by assigned activities with predetermined structure and endpoint, but cross-disciplinary and grade-level boundaries.

- A new analytic tool, crisscrossing topics, shows whether students think and theorize about topics in an interdisciplinary way, leading them to address concepts at and beyond their grade level.

- The research reported indicates that integrating work across topics leads to more productive discourse threads.

\section{Keywords}

Knowledge Building, learning analytics, knowledge creation, discourse analysis, interdisciplinary studies

Submitted: 16.07.2018 - Accepted: 23.08.2019 - Published: 12.13.2019

Corresponding author ${ }^{1}$ Email: a.khanlari@mail.utoronto.ca Address: OISE, University of Toronto, 252 Bloor St. W., 10-229, Toronto, ON M5S 1 V6, Canada.

${ }^{2}$ Email: gaoxia.zhu@mail.utoronto.ca Address: OISE, University of Toronto, 252 Bloor St. W., 10-221, Toronto, ON M5S 1V6, Canada.

${ }^{3}$ Email: marlene.scardamalia@utoronto.ca Address: OISE, University of Toronto, 252 Bloor St. W., 10-226, Toronto, ON M5S 1V6, Canada

\section{Introduction}

Constructivism is a theory of learning that emphasizes the active role of the learner in creating meaning (e.g., Jonassen, Davidson, Collins, Campbell, \& Haag, 1995; Piaget, 1964). Scardamalia and Bereiter (2003) distinguish shallow and deep constructivism according to levels of responsibility and agency that students assume. Knowledge building requires that students engage in sociocognitive processes typically reserved for teachers; for example, setting goals, planning, monitoring work as it proceeds, and evaluating and improving idea coherence (Bereiter \& Scardamalia, 1987; Scardamalia \& Bereiter, 1991, 2006; Tarchi et al., 2013). Engaging students in the complex interactions of a knowledge building culture "captures the natural human tendency to play creatively with ideas, and expands it to the unnatural human capacity to exceed the boundaries of what is known and knowable - to exceed expectations rather than settle into routines" (Scardamalia, 2002, p. 78).

The knowledge building literature includes a number of reports of students engaged in "deep constructivism," exceeding expectations according to developmental norms. For example, elementary school students demonstrate more mature understanding of the nature of science than same-age peers and engage in metadiscourse and promisingness judgments that represent ways of working with knowledge considered advanced for their grade level (Chen, Scardamalia, \& Bereiter, 2015; Chuy et al., 2010; Resendes, Scardamalia, Bereiter, Chen, \& Halewood, 2015). Gan, Scardamalia, Hong, and Zhang (2010) focused on graphical literacy through knowledge building and developed a seven-dimension analytic scale to evaluate student 
graphics. Their participants included one Grade 4 class with experience in knowledge building and a Grade 6 class with no prior experience. The Grade 4 students had, on average, higher scores in graphical literacy than the Grade 6 students. This is in line with Teo (2012), who suggested an indicator of exceeding expectations could be younger students outperforming older students. These various studies have involved students in using Knowledge Forum technology, including its analytic tools specially designed to support knowledge building.

Knowledge building analytics provide various indicators of work with ideas in Knowledge Forum. They include quantitative summaries of note creation and building-on activity (Burtis, 1998); analyses of social structures represented in student online engagement (Oshima, Oshima, \& Matsuzawa, 2012); growth of vocabulary and overlapping vocabulary used in different notes and different domain vocabulary dictionaries (Hong, Scardamalia, Messina, \& Teo, 2015); and metadiscourse reflecting the ability to advance community knowledge (Chen et al., 2015; Resendes et al., 2015; van Aalst, Mu, \& Yang, 2015; Zhang et al., 2015). These tools enable researchers and teachers to evaluate knowledge building communities from different perspectives. The current study aims to extend previous work by developing indicators of crossing disciplinary and grade-level boundaries in knowledge building discourse. Teachers report that students engaged in knowledge building exceed expectations with respect to curriculum standards, teamwork, creative problem solving, and other indicators of what are popularly known as 21 st century competencies. The current work aims to provide research support for teachers' informal assessments while working toward a suite of Knowledge Forum tools to uncover the many dimensions of productive knowledge work that students engage in through knowledge building.

Knowledge building/knowledge creation involves crisscrossing idea landscapes from many perspectives - explorations through which one comes to "feel at home in a conceptual environment" (Scardamalia \& Bereiter, 2016). In this paper, we consider some of what this "crisscrossing idea landscapes" entails and introduce a crisscrossing topics analytic tool to assess the extent to which students integrate concepts from different science topics at or beyond their current grade level into their work. Though not identical to cross-curricular and crosscutting curriculum units, crisscrossing topics is a concept that relates directly to student capacity for interdisciplinary thinking, as suggested by the use of cross-curricular topics. It may also serve as an indicator of exceeding expectations for two reasons:

1. If students connect the core topic of interest shared by community members with other topics, it shows their explorations are not circumscribed by unidimensional curriculum goals

2. If students connect the central topic of interest with topics found in curriculum guidelines for grades higher than their own, this suggests that they are exceeding grade-level expectations

Previous studies (e.g., Cole, Ullman, Gannon, \& Rooney, 2015; Ofsted, 2010; Roberts, 2006) indicated that linking curriculum subjects has the potential to engender creative thinking and metacognition. Therefore, crisscrossing topics not only has the potential to serve as an indicator of performance beyond grade-level expectations, but may also show whether students are engaged in knowledge processes that foster knowledge creation.

In a pilot study, Khanlari, Zhu, Costa, and Scardamalia (2018) explored the extent to which Grade 1 students are able to crisscross science domains. Building on that work, in this study we aim to address the following research questions:

1. Do students in two knowledge building classrooms crisscross science topics while exploring the central topics of interest to the community, indicating interdisciplinary thinking and leading to exploration of topics beyond their grade level?

2. Does crisscrossing topics increase productive knowledge work to support community knowledge advancement?

\section{Review of the Literature}

\subsection{Knowledge Building Technology and Pedagogy}

Twelve principles frame knowledge building as an idea-centred pedagogy with students as epistemic agents creating knowledge through engaging in complex sociocognitive interactions (Scardamalia, 2002; Scardamalia \& Bereiter, 2006). Knowledge Forum ${ }^{\circledR}$ technology is designed according to these principles to support production and refinement of community knowledge (Scardamalia, 2004). Students enter ideas in Knowledge Forum - incorporating questions, observations, and information to advance their understanding of the world - and through social interaction build onto, cite, annotate, and in other ways develop each other's ideas. Rise above is a knowledge building principle that highlights integration of ideas across contexts and communities.

In line with the "idea diversity" principle of knowledge building, students are encouraged to bring into the discourse from the world around real ideas and authentic problems. Idea improvement - another principle — depends on recognizing and respecting others' ideas and working in complex problem spaces to rise above current levels of explanations and create higher 
level conceptual frameworks. Students continually advance community knowledge by taking collective responsibility for advancing community knowledge, not just their own ideas.

\subsection{Integrative Cross-Curricular Thinking}

Interdisciplinary/multidisciplinary studies "can provide relevant, challenging, and enjoyable learning experiences and stimulating contexts to meet the varied needs of children and young people" (Scottish Government, 2008, p. 21). Creativity required for 21 st-century knowledge work frequently arises from interactions between subjects and multidisciplinary problem solving (Sternberg, 2003; Madden et al., 2013) and supports creative thinking and metacognition (e.g., Cole et al., 2015; Ofsted, 2010; Roberts, 2006).

Educators and researchers have proposed teaching and learning methods that connect different topics within and across subjects, and teachers are encouraged to make connections between topics (Ontario Ministry of Education, 2007). For example, the Ontario Ministry of Education (2007) supports the idea of connecting different curricula: "Teachers should ensure that all students have ample opportunities to explore a subject from multiple perspectives by emphasizing cross-curricular learning" (p. 26). Researchers and educators have employed the cross-curricular approach in a variety of class activities, such as reading comprehension (e.g., Aslan, 2016) and daily physical activities (e.g., Wysocky, 2016). Linking ideas across topics provides students with "connections and intellectual tools that are related across the differing areas of disciplinary content and can enrich their application of practices and their understanding of core ideas" (NRC, 2012, p. 233).

Diverse ideas and perspectives naturally require students to assess the quality and viability of their own ideas with multiple epistemic criteria (Bereiter, 1994). To work with ideas in different areas, students also need to construct coherent understanding, identify deeper questions, and work toward increasingly sophisticated conceptualizations (Zhang, Hong, Scardamalia, Teo, \& Morley, 2011).

\subsection{Knowledge Building Analytics}

From a sociocultural perspective of learning, the potential success or failure in education can be explained by the quality of discourse (Mercer, 2007). The importance of discourse is reflected in increasing interest in developing learning analytics to analyze and support high-quality discourse. For knowledge building/knowledge creation, of special interest is the progressive nature of the discourse through which participants advance the state of knowledge (Bereiter \& Scardamalia, 1993; Bereiter, Scardamalia, Cassells, \& Hewitt, 1997; Tsoukas, 2009).

Zhu and Kim (2017) reviewed existing knowledge-building analytic tools. Several provide quantitative summaries and indication of social structures and semantic profiles in Knowledge Forum (e.g., Burtis, 1998; Hong et al., 2015; Oshima et al., 2012; Resendes et al., 2015). Knowledge Building Discourse eXplorer (KBDeX) is a semantically based social network analysis developed specifically to analyze knowledge building discourse (Oshima et al., 2012). KBDeX analyzes semantic network structures of collective discourse and displays the student network (i.e., how students connect), word network (i.e., how words connect), and discourse network (i.e., how notes connect). Other tools are used to analyze the growth of vocabulary in a specific domain, compare the vocabulary used in student notes with predefined expert vocabulary, or show the overlap of vocabulary in different notes (e.g., Hong et al., 2015; Resendes et al., 2015). For example, the "semantic overlap" tool displays the overlapping words or phrases in different notes or sets of notes or texts, making evident the terms that overlap in student discourse and curriculum guidelines or convey idea similarity between student notes based on the key terms contained in those notes (Hong et al., 2015). Other tools aim to help teachers and students plan, monitor, and evaluate ideas/themes in their community discourse (Chen et al., 2015; van Aalst et al., 2015; Zhang et al., 2015). For example, the "promising ideas" tool helps students select, aggregate, and display ideas that they think deserve the community's subsequent time and effort to lead in the most productive direction (Chen et al., 2015).

Within the context of knowledge building, several studies have used the available analytic tools and focused on vocabulary growth as an indicator of knowledge building. For example, Sun, Zhang, and Scardamalia (2010) investigated how students develop vocabulary knowledge in sustained knowledge building practice by analyzing the lexical frequency profiles, grade levels of new words, and grade levels of domain-specific vocabulary. Chen, Ma, Matsuzawa, and Scardamalia (2015) reported a longitudinal study of the development of productive vocabulary of Grade 1 to Grade 6 students in knowledge building. They analyzed lexical richness, lexical frequency, words beyond the first 1,000 English common words, and traced new vocabulary occurring during each year.

The issue we aim to assess in the current research is the extent to which students incorporate cross-domain concepts into their discourse that map onto concepts at and beyond their grade level according to curriculum guidelines. 


\section{Method}

As Figure 1 shows, the dataset used for this study is comprised of two online databases in Knowledge Forum: 376 notes written by Grade 1 students, exploring "water" and "water cycle" for three months and 272 notes written by Grade 4 students exploring "rocks and minerals" for three months. In both classes, there were 20 students with an equal number of boys and girls. Following the "real ideas, authentic problems" principle of knowledge building, students in both classes raised issues they were interested in and deepened ideas and explorations through ongoing questioning, research, face-to-face talks (KB Talks), and work in Knowledge Forum to generate theories, questions, alternate explanations, record new information from searching or researching and so forth. An element of productive knowledge building discourse includes occasional periods of "metadiscourse" - discourse about discourse (Bereiter \& Scardamalia, 2010). Integrated hands-on activities and experiments (e.g., water freezing and evaporation experiments) further support understanding, as do "KB Talks" in which students sit in a circle, discussing their ideas and introducing new ideas and concepts to their communities. All students were expected to type their notes themselves, but before each session ended, the teachers and the researcher helped the students who were struggling with writing to enter their notes into Knowledge Forum. Students were encouraged to focus on expressing their ideas without concern for spelling.

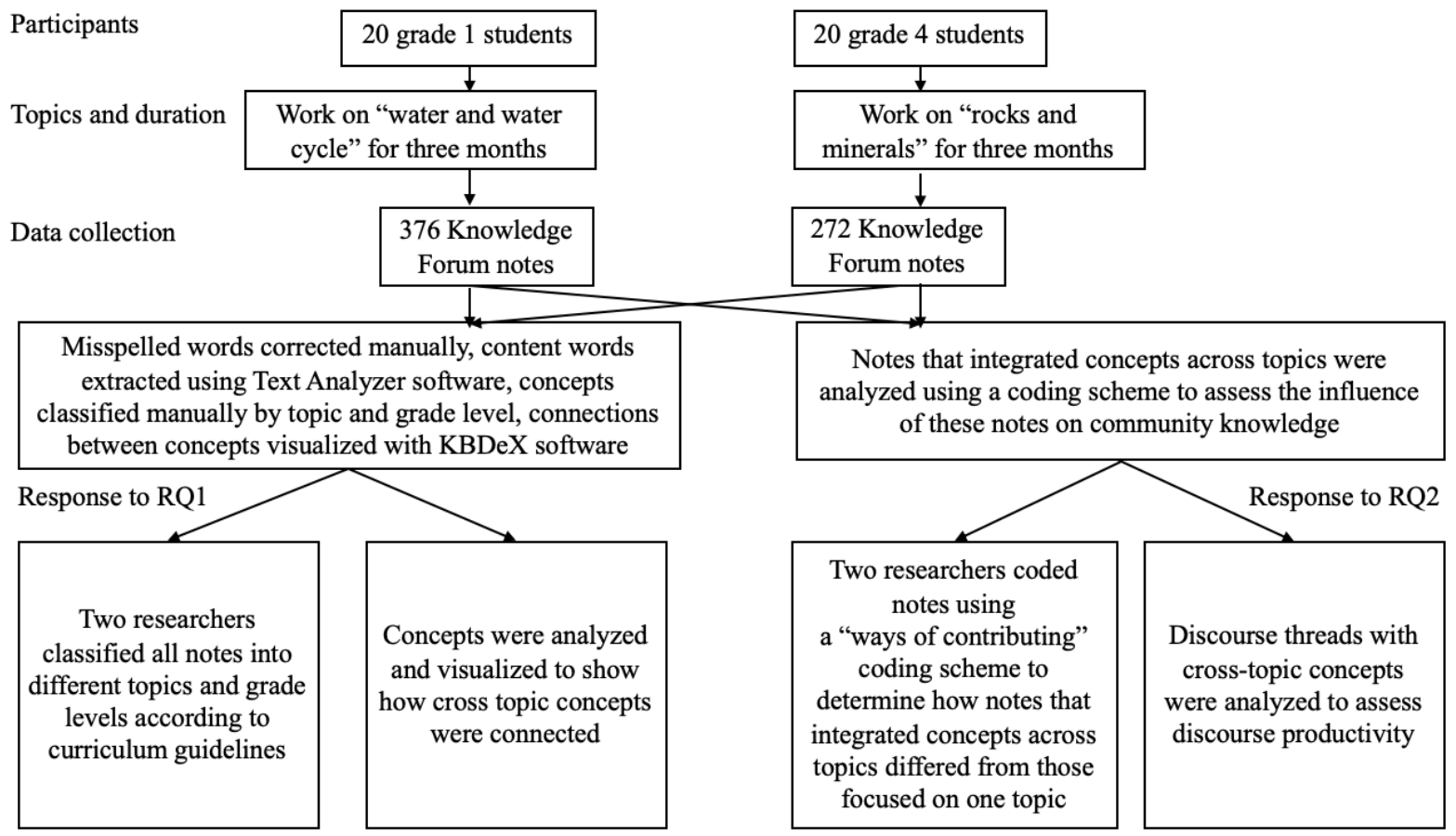

Figure 1. Diagram of the study protocol

To address the first research question, we employed a lexical analysis tool called Text Analyzer ${ }^{\circledR}$ to extract all the words used in notes posted on Knowledge Forum. Text Analyzer ${ }^{\circledR}{ }^{1}$ is free software that allows users to find words and phrases and their related frequencies. This tool does not remove stop words or associate concepts with domains, so to determine topic overlap with different conceptual domains we reviewed the words and phrases and classified concepts manually according to scientific concepts found in the Ontario Science Curriculum (Ontario Ministry of Education, 2007). In this process, misspellings were corrected; words like "atoms, adam, atomms, atom, adums, adames, atams, adem" were all considered as "atom." Words with the same root such as "erupt, erupting, erupted, erupts, eruption" were considered as the same word. Two raters first engaged in a training session and independently coded all the words written by Grade 4 students as scientific or non-scientific concepts. They discussed disagreements and reached what can be considered good agreement (Cohen $\mathrm{K}=0.64)$, then coded words written by Grade 1 students. For both grades, scientific concepts were categorized into different topics (e.g.,

${ }^{1}$ https://www.online-utility.org/text/analyzer.jsp 
growth and changes in animals; air and water in the environment; rocks and minerals; space) according to the science topics in different grades to reveal working across science topics.

To analyze capacity for crisscrossing topics further, we imported all scientific words in student notes into KBDeX to examine connection between these words. KBDeX explores semantic network structures of collective discourse and displays word and discourse networks (Oshima et al., 2012). In this study, we used KBDeX to map the network structure of discourse based on cross-topic words. With a Knowledge Forum note as a unit, one would crisscross two topics if at least one concept from each of the two topics appears in a single note. In addition to KBDeX visualizations, we reviewed the notes in which the connected concepts were used to explore how and in what context students made connections between concepts.

To address the second research question, we conducted two analyses. First, we employed a coding scheme called "ways of contributing" (Chuy et al., 2011) and coded all the notes to analyze the discourse qualitatively. In an attempt to examine the kinds of contributions students make in knowledge building environments, Chuy and colleagues (2011) analyzed student discourse. They developed a systematic inventory of "ways of contributing" to knowledge building discourse with six main categories (questioning, theorizing, obtaining information, working with information, syntheses and analogies, and supporting discussion) and 24 subcategories (e.g., proposing an explanation, improving an explanation, synthesizing information). This coding scheme, which has been widely used to assess contributions in knowledge building communities, enables us to qualitatively analyze student discourse and examine how cross-domain notes contribute to knowledge building discourse.

\section{Results}

\subsection{Criss-Crossing Science Topics}

Figures 2 and 3 show topics by grade level corresponding to curriculum guidelines that Grade 1 and Grade 4 students discussed in their online discourses. We use different colors to show frequency: the words that appeared more than ten times are displayed in red; words that appeared 3 to 9 times are in orange/brown; words that appeared 1 to 2 times are in blue. The scientific concepts related to different topics are displayed in different circles. As Figure 2 shows, the main topic discussed by the Grade 1 students was water and the water cycle. However, students did not limit their discussions to concepts directly related to water (e.g., water, raindrop, evaporation). Rather, they made connections between water and other topics such as the space system from Grade 6 (e.g., moon, Mars, atmosphere, Jupiter, meteor, gravity), rocks and minerals from Grade 4 (e.g., lava, volcano, sand), biodiversity from Grade 6 (e.g. animals, butterfly, plant, bacteria), matter and energy from Grade 2, and properties of and changes in matter from Grade 4 (e.g. cold, fire, pressure, temperature). Concepts such as sun, atmosphere, and sky relate to both water and the water cycle and the space system; if a keyword concept is common to two topics, it is positioned in the overlapping area. Although the children were in Grade 1, they discussed topics from Grade 2 to Grade 6, indicating beyondgrade-level expectations in terms of scientific concepts brought into their discourse.

As Figure 3 shows, Grade 4 students mainly explored and discussed different aspects of rocks and minerals. For example, they discussed the properties of rocks (e.g., color, layer, texture), the formation of rocks (e.g., magma, lava, continental plate, volcano), and different forms of rocks and minerals (e.g., diamond, calcite, jewelry). Similarly, they explored other topics such as space from Grade 6 (e.g. galaxy, solar system), light and sound from Grade 4 (e.g., noise, light speed, rumbling), conservation of energy and resources from Grade 5 (e.g., wood, fossil fuel, fire, force field), the water system from Grade 8 (e.g., rain, flood, sea, water), atoms, elements, and compounds from Grade 9 (e.g., atom, molecule, nucleus, electron, particle), biodiversity from Grade 6 and growth and changes in animals from Grade 2 (e.g., reptile, amphibian, insect). The topics the students worked on range from Grade 2 to Grade 9, suggesting that Grade 4 students went beyond curriculum expectations in terms of concepts brought into their discourse.

To show how these different topics are connected, we used KBDeX to visualize the network of concepts discussed by students. In Figure 4 and Figure 7, we have selected concepts that are core to the main topic of discussion for Grades 1 and 4 ("water" and "rock," respectively). In these networks, words are connected if the notes containing those words have at least one common keyword. Lines in these networks show the strength of connections among words; the thicker the line, the stronger the connection. Figures 4, 5, and 6 provide a more in-depth look at the Grade 1 network of concepts, while Figures 7, 8, and 9 provide a more in-depth look at the Grade 4 network of concepts. 


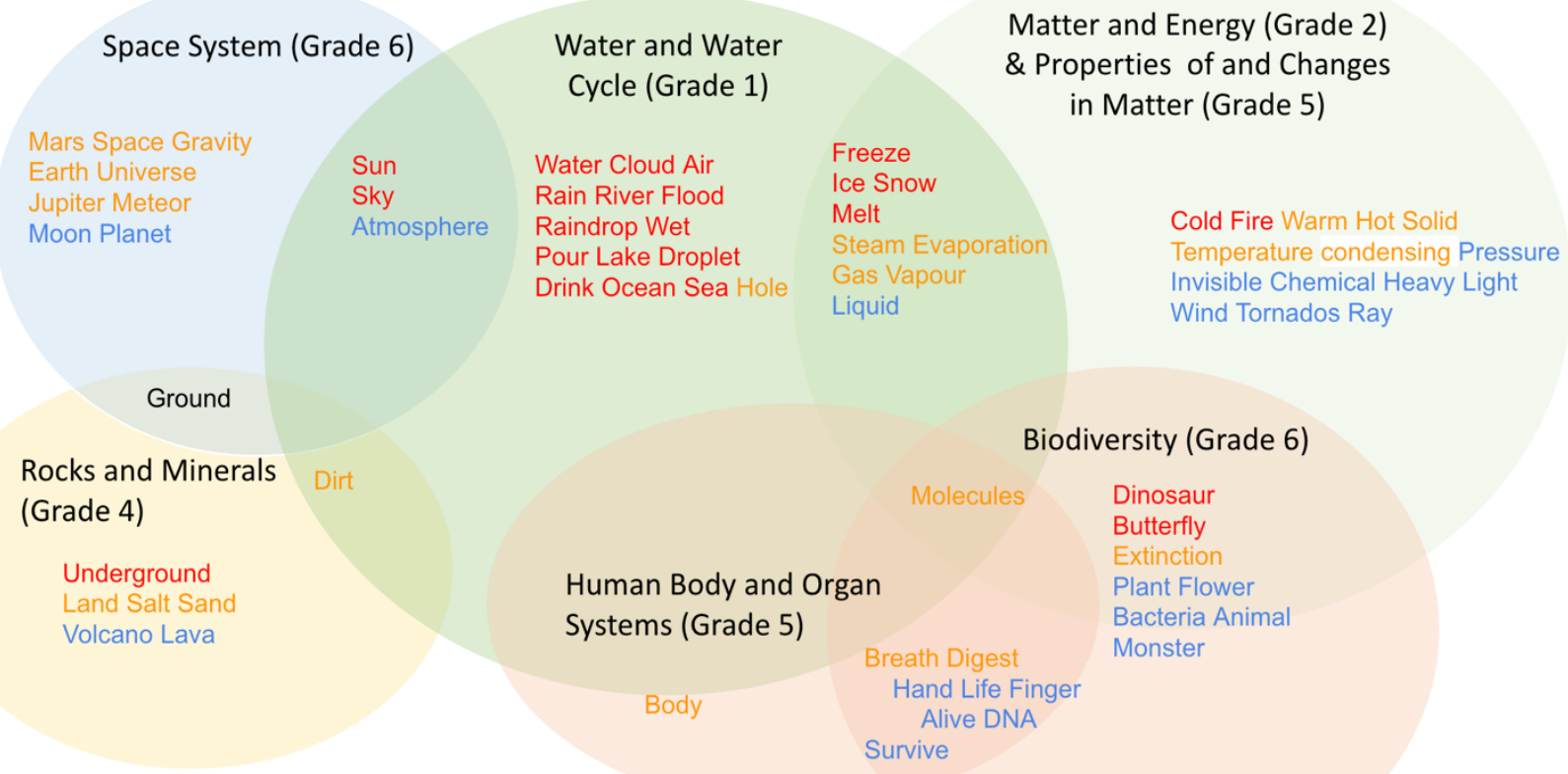

Figure 2: Concepts in Grade 1 student discourse: topics and grade levels of concepts according to Ontario science curriculum guidelines.

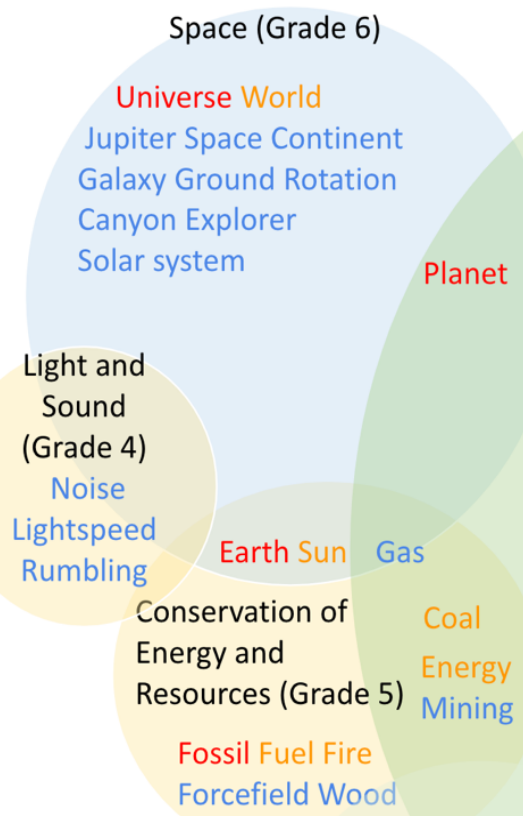

\section{Rocks and Minerals}

(Grade 4)

Rock Lava Volcano Mineral Magma

Diamond Crust Land Sand

Hardness Mountain Bone Layer

Mantle Place Matter Plate Color

Dirt Earthquake Hole Meteorite

Shape Stone Texture Explosion

Boom Crack Cave Dark Gem Soil

Bulge Eruption Explosion Scientist

Carbon Stage Crystal Surface Solid

Pure Lump Gravel

Topaz Vesuvius Carat Formation

Corundum Spear Obsidian

Orthoclase Gypsum Block Pumice

Ash Pressure

Debris Calcite Flourite

Skeleton Salt Jewelry

Quart Ripple
Growth and

Changes in Animals

(Grade 2)

Evolution Animal Reptile

Amphibian Insect Generation

Gorilla Land creature Kimberlite

pipes

People Life
Creature
Nature Person
Human Darwin

People Life

Creature

Earth Nature Person

Planet

Atoms, Elements, and Compounds (Grade 9) Atom Molecule

Biodiversity (Grade 6)

Plant Survival

Species Dinosaur

Liopleurodon

Brachiosaurus

Periodic mass extinctions

\section{Water system (Grade 8) \\ Water Ocean Ice \\ Sea Rain Flood \\ Lake}

Figure 3: Concepts in Grade 4 student discourse: topics and grade levels of concepts according to Ontario science curriculum guidelines. 
Figure 4 shows all the scientific words and their connections used by Grade 1 students. The red words are directly connected with the word water. As can be seen in this graph, students connected the main concept (i.e., water) to a variety of concepts, including gravity, light, space, and digest.

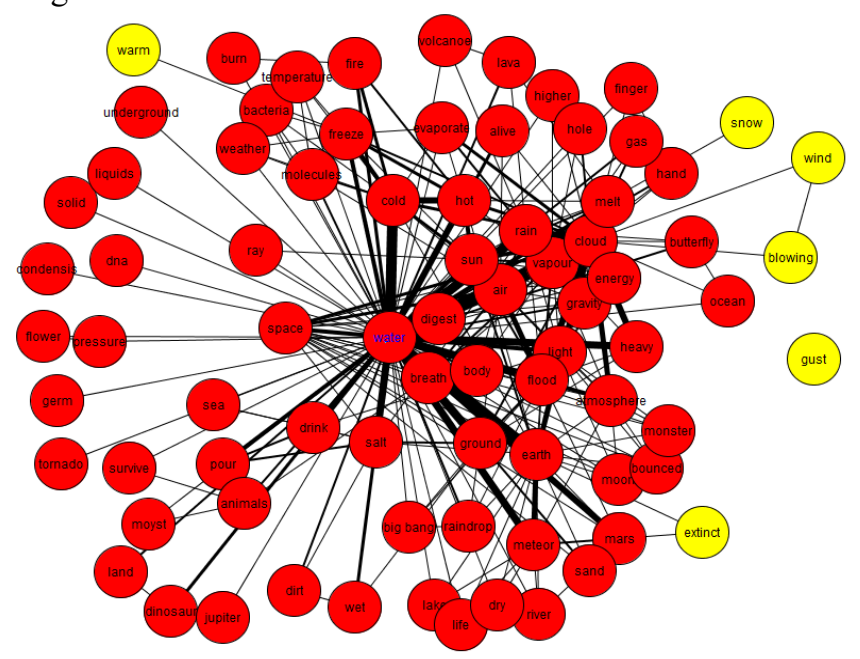

Figure 4: A network of scientific words discussed by Grade 1; red indicates words directly connected with the main concept "water."

Figure 5 shows that during their discussion of water and the water cycle, students made links between "water" and "space"; students included space concepts such as atmosphere, cloud, and Mars (see words highlighted in red), found in the Grade 6 curriculum. Other words related to water (e.g., cloud, cold) and space (e.g., gravity, moon) are placed around the word water. We reviewed the notes containing these words to identify how students made connections between these concepts. One of the students, for instance, had written:

My theory: ... On top of Mars, there is a mountain of snow and ice... There used to be a river on Mars...

This student note connected three topics: 1) space, 2) properties of and changes in matter, and 3) water and the water cycle.

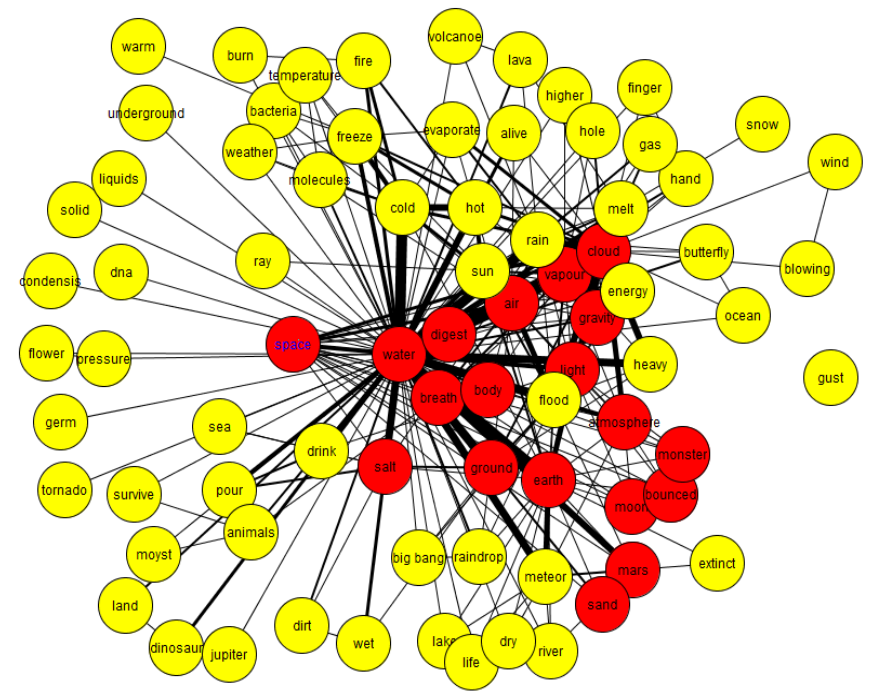

Figure 5: A network of scientific words discussed by Grade 1; red indicates words directly connected with "space."

In Figure 6, we have selected a word located at the periphery of the concept network. A peripheral word is one not connected with other scientific concepts; this Figure shows the peripheral word "gust." 


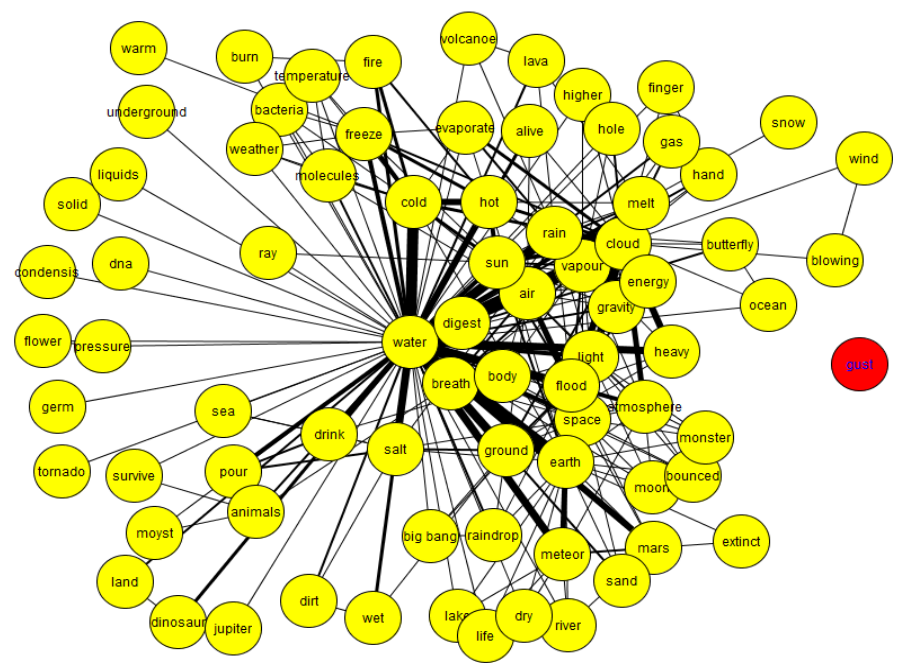

Figure 6: A network of scientific words discussed by Grade 1; red indicates the word "gust" as a peripheral concept.

Figure 7 shows the network of different concepts used by Grade 4 students. The words in red are the words students connected with "rock," which was part of the main topic of discussion (rocks and minerals). As can be seen in Figure 7, "rock" is connected with several concepts used by the students, except for some concepts such as the Grade 6 topic of biodiversity (e.g., creature, Darwin, extinction) and some concepts of the Grade 6 topic of space (e.g., rotate, Jupiter, equator).

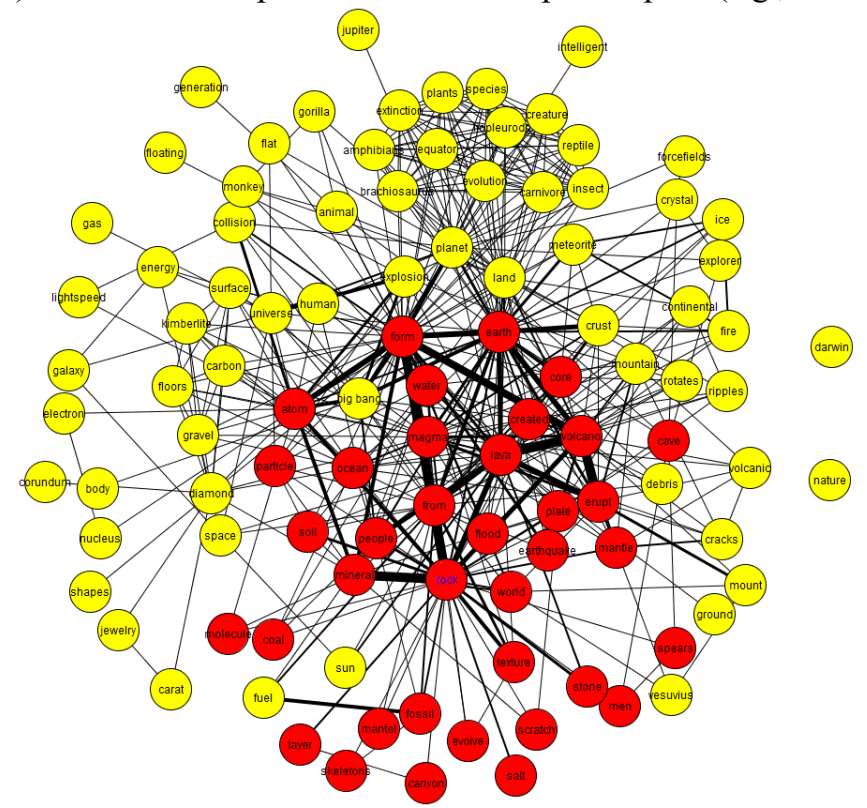

Figure 7: A network of scientific words discussed by Grade 4; red indicates words directly connected with the main concept "rock."

In Figure 8, we highlight "planet" and connected concepts in red. The concept "planet" is included in biodiversity (Grade 6) and space (Grade 6) in the curriculum. In student discourse, "planet" is connected with concepts of the topic of rock and minerals (e.g., lava, core, crust); growth and changes in animals (e.g., insects, reptile); biodiversity (e.g., Brachiosaurus, species, plant); and space (e.g., Jupiter, explorer). We reviewed the notes to identify how the word "planet" is connected with the highlighted concepts in Figure 8. For example, we found the following note that starts with the Knowledge Forum bettertheory scaffold "[A better theory] is that it is a place where atoms collided and formed planets. Then life form came and it evolved to the life forms you see today. That is how humans came to be." A connection to biodiversity was made by asking "is there intelligent life on other planets?" and with elements, and compounds and biodiversity by stating "Amazing planet earth ... the first plants and insects appeared on land 400 million years ago..." 


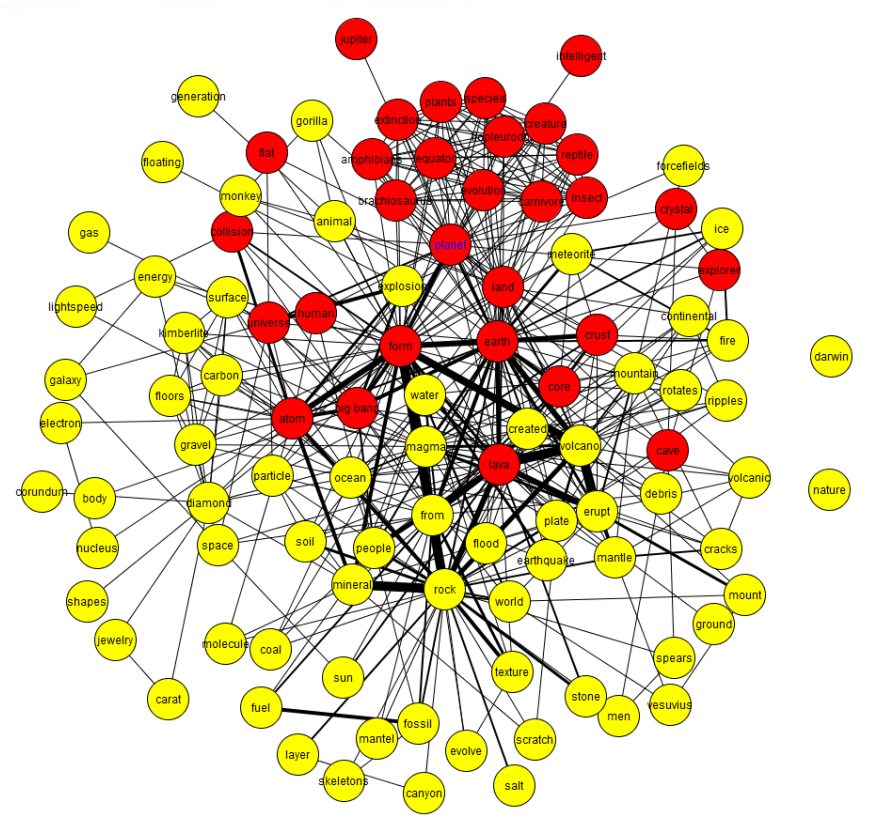

Figure 8: A network of scientific words discussed by Grade 4; red indicates words directly connected with the concept of "planet."

In Figure 9, we highlighted a few concepts located at the periphery of the concept network used by Grade 4 students. These peripheral words ("Darwin," "nature," and "forcefield") which do not belong to the main topic (rocks and minerals) are not connected with other concepts. In reviewing student notes, we found that a student introduced "Darwin" by writing "How did Darwin get his ideas?"; "nature" was introduced in the note "I think so too, but is crushed by nature"; and "forcefields" was introduced in "the city probably had some forcefields."

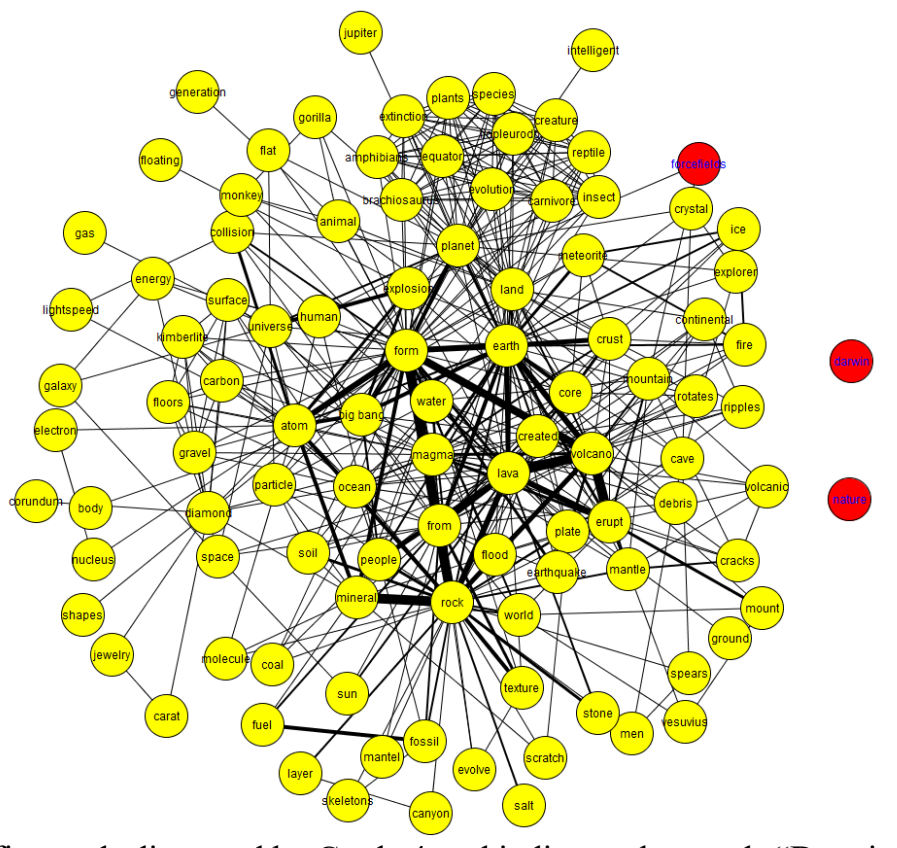

Figure 9: A network of scientific words discussed by Grade 4; red indicates the words "Darwin," "nature," and "forcefield" as peripheral concepts.

\subsection{Crossing Science Topics and Community Knowledge Advancement}

In order to address the second research question and examine whether crisscrossing topics helps students improve their understanding of the core concept, we used a "ways of contributing" coding scheme. We first coded each note then employed a productive thread analysis to examine whether cross-topic notes result in advancing community knowledge. Two raters coded 
and categorized all the notes using the "ways of contributing" scheme; each note could fall under more than one category. The agreement rate was $99.27 \%$ for Grade 1 and $99.57 \%$ for Grade 4 . After identifying scientific concepts, we reviewed all the notes to identify cross-topic notes. Tables 1 and 2 provide summaries of the "ways of contributing" categories and subcategories (subcategories numbered according to Chuy et al., 2011) of the notes containing cross-topic words.

As Table 1 shows, in Grade 1, 59.5\% of all the questions ( 69 out of 116 notes) were cross-topic notes. Likewise, $63.2 \%$ of all the theorizing notes (108 out of 171) were cross-topic notes. In the third main category, out of the total 33 notes categorized as "obtaining information," 22 notes $(66.7 \%)$ were cross-topic notes. In the other main categories, $83.3 \%$ of the notes coded as "working with information" (10 notes out of the total 12), 100\% of the notes coded as "synthesizing and comparing," and $56.2 \%$ of the notes coded as "supporting discussion" were cross-topic notes.

Table 1: Cross-Topic Notes in "Ways of Contributing" Categories, Grade 1

\begin{tabular}{|c|c|c|c|}
\hline $\begin{array}{l}\text { Ways of } \\
\text { Contributing: } \\
\text { Major } \\
\text { Categories }\end{array}$ & $\begin{array}{l}\text { Ways of Contributing: } \\
\text { Sub-categories }\end{array}$ & Total & $\begin{array}{l}\text { Cross-topic } \\
\text { notes }(\%)\end{array}$ \\
\hline \multirow[t]{2}{*}{ Questions } & 1. Explanation questions (why/how something happens) & 95 & $60(63.2 \%)$ \\
\hline & 3. Factual questions (who/what/where/when questions) & 21 & $9(42.9 \%)$ \\
\hline \multirow[t]{4}{*}{ Theorizing } & 4. Proposing an explanation & 76 & $44(57.9 \%)$ \\
\hline & 5. Supporting an explanation & 46 & $26(56.5 \%)$ \\
\hline & 6. Improving an explanation & 24 & $22(91.7 \%)$ \\
\hline & 7. Seeking an alternative explanation & 25 & $16(64 \%)$ \\
\hline \multirow{2}{*}{$\begin{array}{l}\text { Obtaining } \\
\text { Information }\end{array}$} & 11. Introducing new information from sources & 18 & $13(72.2 \%)$ \\
\hline & 12. Introducing new information from experience & 15 & $9(60 \%)$ \\
\hline \multirow[t]{3}{*}{$\begin{array}{l}\text { Working with } \\
\text { Information }\end{array}$} & $\begin{array}{l}\text { 15. Providing an evidence or reference to support a particular } \\
\text { idea }\end{array}$ & 8 & $6(75 \%)$ \\
\hline & $\begin{array}{l}\text { 16. Providing an evidence or reference to discard a particular } \\
\text { idea }\end{array}$ & 3 & $3(100 \%)$ \\
\hline & 17. Weighing different explanations & 1 & $1(100 \%)$ \\
\hline \multirow{3}{*}{$\begin{array}{l}\text { Synthesizing } \\
\text { and } \\
\text { Comparing }\end{array}$} & $\begin{array}{l}\text { 19. Synthesizing and interpreting information from } \\
\text { authoritative sources }\end{array}$ & 4 & $4(100 \%)$ \\
\hline & 20. Using an analogy & 3 & $3(100 \%)$ \\
\hline & 21. Initiating rise-above entry & 6 & $6(100 \%)$ \\
\hline \multirow{2}{*}{$\begin{array}{l}\text { Supporting } \\
\text { Discussion }\end{array}$} & 23. Giving an opinion (students' personal opinions) & 25 & $17(68 \%)$ \\
\hline & 24. Acting as a mediator & 7 & $1(14.3 \%)$ \\
\hline
\end{tabular}

As Table 2 shows, in Grade 4, 39.1\% of all the "questions" (34 out of 87 notes) were cross-topic notes. In the "theorizing" category, out of the total 136 notes coded as theorizing notes, 60 notes $(44.1 \%)$ were cross-topic notes. In the third main category, $52 \%$ of all the "obtaining information" categories were cross-topic notes. In other main categories, $16.7 \%$ of the 
notes coded as "working with information" (one note out of the total six) and $4.7 \%$ of the notes coded as "supporting discussion" (two notes out of the total 43 notes) were cross-topic notes.

Table 2: Cross-Topic Notes in "Ways of Contributing" Categories, Grade 4

\begin{tabular}{|c|c|c|c|}
\hline $\begin{array}{l}\text { Ways of } \\
\text { Contributing: } \\
\text { Major } \\
\text { Categories }\end{array}$ & $\begin{array}{l}\text { Ways of Contributing: } \\
\text { Sub-categories }\end{array}$ & Total & $\begin{array}{c}\text { Cross-topic } \\
\text { notes }(\%)\end{array}$ \\
\hline \multirow[t]{2}{*}{ Questions } & 1. Explanation questions (why/how something happens) & 51 & $16(31.4 \%)$ \\
\hline & 3. Factual questions (who/what/where/when questions) & 36 & $17(47.2 \%)$ \\
\hline \multirow[t]{4}{*}{ Theorizing } & 4. Proposing an explanation & 66 & $28(42.4 \%)$ \\
\hline & 5. Supporting an explanation & 43 & $18(41.9 \%)$ \\
\hline & 6. Improving an explanation & 13 & $8(61.5 \%)$ \\
\hline & 7. Seeking an alternative explanation & 14 & $6(42.8 \%)$ \\
\hline \multirow{3}{*}{$\begin{array}{l}\text { Obtaining } \\
\text { Information }\end{array}$} & 8. Asking or looking for evidence to support a particular idea & 5 & $2(40 \%)$ \\
\hline & 11. Introducing new information from sources & 43 & $23(53.5 \%)$ \\
\hline & 12. Introducing new information from experience & 4 & $2(50 \%)$ \\
\hline $\begin{array}{l}\text { Working with } \\
\text { Information }\end{array}$ & 15. Providing evidence or reference to support a particular idea & 6 & $1(16.7 \%)$ \\
\hline $\begin{array}{l}\text { Synthesizing } \\
\text { and } \\
\text { Comparing }\end{array}$ & 19. Initiating rise-above entry & 1 & $0(0 \%)$ \\
\hline \multirow{2}{*}{$\begin{array}{l}\text { Supporting } \\
\text { Discussion }\end{array}$} & 23. Giving an opinion & 34 & $2(5.9 \%)$ \\
\hline & 24. Acting as a mediator & 9 & $0(0 \%)$ \\
\hline
\end{tabular}

In the next step, we examined discussion threads in terms of productivity to explore whether the cross-topic notes help to improve community knowledge. In the dataset used for this work there were a total of 111 discussion threads in the Grade 1 database, and a total of 91 discussion threads in the Grade 4 database. In Grade 1, among the total 111 threads, 19 threads $(17 \%)$ were identified as productive. Out of these 19 productive threads, $16(84 \%)$ were identified as cross-topic productive threads, meaning that at least one cross-topic note in those threads was coded as "theorizing: improving an explanation" and no non-cross-topic note was coded as such. Therefore, the productivity of these threads relates to the existence of cross-topic notes. There was one productive thread that had both one cross-topic note and one non-cross-topic note. Two other productive threads $(8 \%)$ were identified as non-cross-topic threads; in each, at least one non-cross-topic note rated as improving the explanation, while no cross-topic note improved the explanations in those threads.

In Grade 4, of the 91 threads in total, 12 (13\%) were identified as productive, eight of which (67\%) were identified as cross-topic threads, because at least one cross-topic note improved the explanation of the thread. The remaining four productive threads (33\%) were identified as non-cross-topic productive threads, because there was at least one non-cross-topic note in those threads that improved the explanation of the discussion.

\section{Discussion and Conclusion}

Maute (1992) stated that "cross-curricular connections are connections between two or more areas of study that are made by teachers within the structure of their disciplines" (p. 73). The literature suggests that to have a successful cross-curricular 
classroom, the teacher should carefully design course plans and activities to make connections between different curricula or different concepts (Savage, 2010). As is evident from our results here, students as early as Grade 1 cross science borders and extend knowledge boundaries on their own, leading to explorations of a core concept from the many perspectives grounded in experiences and interests of community members. As discussed in the results sections, the epistemic agency afforded them in their knowledge work led Grade 1 students to discuss topics found in curriculum guidelines for Grades 2 to 6 and Grade 4 students in curriculum guidelines for Grades 2 to 9. Previous research has shown that when students take collective responsibility for advancing community knowledge, they identify gaps in understanding that help them deepen their understanding (van Aalst \& Cummings, 2006). The current research suggests that these young students have a natural tendency to explore issues beyond those addressed in curriculum guidelines for their grade levels.

Creative thinking often arises from interactions between ideas from different domains (Cole et al., 2015; Ofsted, 2010; Roberts, 2006). Results from this cross-topic notes analysis show that students in Grades 1 and 4 engaged in creative, interdisciplinary thinking resulting in productive knowledge threads. In knowledge building communities, participants bring ideas and authentic problems from their different perspectives to their explorations, resulting in divergent knowledge topics rather than work that advances along a predefined or fixed path. As Scardamalia and Bereiter (2016) explain, knowledge creators know their way around a domain because of the multifaceted, divergent paths they explore. Science curricula in many countries are subject-based with development of a scientific concept as one of its primary goals (Fensham, 2008). Knowledge building, by turning high levels of agency over to students for exploring issues broadly related to the core concept, encourages crisscrossing science domains, thus increasing chances of sustained creative work.

Developing an analytic tool to assess crisscrossing topics has the potential to help researchers and teachers examine the extent to which students are engaged in integrating ideas. The majority of "questions," "theorizing," and "obtaining information" notes in both Grades 1 and 4 are cross-topic notes. These three categories are of special interest. Several studies have shown that questions push dialogue forward and make the discourse more sustainable and productive, which can help increase explanatory coherence (e.g., Khanlari, Resendes, Zhu, \& Scardamalia, 2017; Resendes, 2014). The fact that many questions involved cross-topic notes shows that students' authentic problems and puzzlements help drive sustainable and productive interdisciplinary discourse. Theorizing notes underscore scientific inquiry and construction of new scientific knowledge (Carey \& Smith, 1993). As Chuy et al. (2011) stated, constructing theoretical explanations and building on theories helped students advance their understanding of scientific knowledge creation. Knowledge building aims to provide opportunities for students to engage in theory building by taking collective responsibility for pursuing deeper understanding and explanations of the world (Bereiter \& Scardamalia, 2012). Results suggest that concepts from extended fields of science are used in theorizing notes, seemingly a reflection of student effort to extend and deepen their understanding of the world around them.

According to Koestler, improving an explanation can be achieved in different ways, including connecting disparate facts, introducing new evidence, elaborating an existing idea, or making a conceptual leap (Koestler, 1964). For 66.7\% of Grade 1 and $52 \%$ of Grade 4 students, notes coded as "obtaining information" are cross-topic notes. This suggests that students are searching for information to advance their understanding and that the new information helps them elaborate and connect ideas across domains. In addition, as stated by Resendes (2014), in explanation-seeking discourse, students use a wide range of facts, both from authoritative sources, empirical observations, and experiments to build upon their original ideas and increase the coherence of their theories. While crisscrossing different science topics, Grade 1 and Grade 4 students introduced new information from resources or experience, and Grade 4 students requested evidence to support ideas, helping explanationseeking discourse advance their knowledge objectives. Furthermore, research conducted by Chuy et al. (2011) suggests that "theorizing" and "information" contributions predict individual knowledge advancement. In the current study, the majority of theorizing and information-obtaining notes were cross-topic notes suggesting that such notes may serve as "hotspots" for knowledge advancement. Another interesting finding of the current study is that $100 \%$ of the Grade 1 notes coded as "synthesizing and comparing" belonged to cross-topic notes. Synthesizing notes such as "rise-above" notes are intended, as discussed by Scardamalia and Bereiter (2006), to "synthesize ideas, create historical accounts and archives, reduce redundancy, and in other ways impose higher levels of the organization on ideas." Interestingly, Grade 1 student efforts to achieve higher levels of organization appear as cross-topic notes.

The results of the productivity threads analysis show, in both grades, that productive threads typically include cross-topic threads. In Grade 1, about $84 \%$ of the productive threads are cross-topic threads, another 5\% include cross-topic and noncross-topic notes, and only about $11 \%$ do not include cross-topic notes. In Grade 4, about $67 \%$ of the productive threads are cross-topic notes, while only $33 \%$ include no cross-topic notes. Cross-topic notes leading to productive discourse support the knowledge building perspective that exploration of "real ideas, authentic problems" leads to multifaceted explorations that enrich understanding. Results help to counteract the concern that open exploration will lead to disconnected, off-topic discourses that get nowhere. It is important to appreciate that Knowledge Forum, designed to support knowledge building 
discourse, was used in these classes. Accordingly, students contributed their ideas to a collective community space. Taking collective responsibility for advancing community knowledge is supported by various analytic tools that provide higher-order visualizations and reconceptualizations of the community discourse, helping students become discursively connected (Resendes et al., 2015) and "rise above" separate inquiries. When students work on ideas and problems that they really care about, contributing ideas to a common space, they identify crosscutting ideas and concepts that expand their thinking and crisscross idea landscapes. This extends the range of science concepts that students explore. Improving community knowledge, over-and-above individual achievement, has the potential to "set a knowledge building classroom off as profoundly different from even the best of traditional and modern classrooms" (Scardamalia, 2002, p. 77). A challenge for knowledge building analytics is to develop tools to support the advancement of community knowledge. Results show cross-topic notes support productive idea threads, thus they may well serve as markers of discourse that advances knowledge objectives.

Within the knowledge building literature, several studies have examined the overlap between student discourse and an expert corpus or curriculum glossary (e.g., Costa, 2016; Resendes, 2014). In such studies, the more students are talking scientifically (i.e., using words from expert corpus/curriculum glossaries), the more they have met the learning expectations. Of course there is always a danger that "topics are merely checked off and students move on whether there is understanding or not" (Messina, 2001, p. 21). The analytic tools proposed in the present study represent an attempt to explore whether students cross knowledge borders, providing a more interdisciplinary framework for the analysis, with the addition of crossing gradelevel borders, used to indicate the extent to which students may be exceeding, not simply meeting expectations set forth in curriculum guidelines.

Another contribution of this study is the conceptual analysis and corresponding work to develop a tool to determine the extent to which student discourse is addressing knowledge goals. The study demonstrates the potential of identifying concepts and related topics by grade levels for use as a library of terms corresponding to desired goals and entering them into software environments - in this case Knowledge Forum. Then, while students build knowledge, they can see the conceptual profile of the community and their contributions to it. Visualizations of the concepts in diverse topics and grade levels can provide feedback to students, as well as to teachers and parents, to support further knowledge creation. Future work will explore the nature of effective visualizations and ways that concurrent, embedded, and transformative assessment - a principle of knowledge building - can support natural student inquisitiveness toward the "disciplined creativity" of mature knowledge producers (Scardamalia \& Bereiter, 2003). A limitation of the current work that needs to be addressed in future work will be automating the work that researchers handled manually (correcting misspellings and classifying concepts in student texts). Raters had strong agreement, but this may relate to their background in the domain. It may be hard to achieve agreement under other conditions, and this labour-intensive process needs to be streamlined.

The main limitation of the study to be addressed in future research relates to the extent to which crisscrossing topics leads to deep understanding of those concepts. Hong and Scardamalia (2014) used lexical analysis involving domain-specific words to characterize the development of expertise within a community. Creative work with ideas and expertise are complementary, suggesting that cross-topic explorations may also prove useful as indicators of development of understanding in the domains addressed. Future studies will incorporate analyses over extended periods to track the productive use of new concepts, combined with discourse analysis to determine the quality and depth of conceptual understanding as rated by domain experts. The goal will be to ensure that the analytic tool meets the expectations of experts in the domain so that we can better characterize the extent to which and the ways in which students in knowledge building communities meet and possibly exceed expectations.

\section{Declaration of Conflicting Interest}

The authors declared no potential conflicts of interest with respect to the research, authorship, and/or publication of this article.

\section{Funding}

This research was made possible by a grant from the Social Sciences and Humanities Research Council of Canada entitled "Digitally Mediated Group Knowledge Processes to Enhance Individual Achievement in Literacy and Numeracy," Protocol Reference \#32092.

\section{References}

Aslan, Y. (2016). The effect of cross-curricular instruction on reading comprehension. Universal Journal of Educational Research, 4(8). 1797-1801. http://dx.doi.org/10.13189/ujer.2016.040808

Bereiter, C. (1994). Implications of postmodernism for science, or science as progressive discourse. Educational Psychologist, 29, 3-12. http://dx.doi.org/10.1207/s15326985ep2901 1 
Bereiter, C., \& Scardamalia, M. (1987). An attainable version of high literacy: Approaches to teaching higher-order thinking skills in reading and writing. Curriculum Inquiry, 17, 9-30. http://dx.doi.org/10.1080/03626784.1987.11075275

Bereiter, C., \& Scardamalia, M. (1993). Surpassing ourselves: An inquiry into the nature and implications of expertise. Chicago: Open Court.

Bereiter, C., Scardamalia, M., Cassells, C., \& Hewitt, J. (1997). Postmodernism, knowledge building, and elementary science. The Elementary School Journal, 97(4), 329-340. http://dx.doi.org/10.1086/461869

Burtis, J. (1998). Analytic toolkit for knowledge forum. Centre for Applied Cognitive Science, Ontario Institute for Studies in Education/University of Toronto.

Chen, B., Ma, L., Matsuzawa, Y., \& Scardamalia, M. (2015). The development of productive vocabulary in knowledge building: A longitudinal study. In O. Lindwall, P. Hakkinen, T. Koschmann, P. Tchounikine, \& S. Ludvigsen (Eds.), Exploring the Material Conditions of Learning: Proceedings of the 11th International Conference on Computer Supported Collaborative Learning (CSCL 2015), 7-11 June 2015, Gothenburg, Sweden (Volume 1, pp. 443-450). International Society of the Learning Sciences. https://doi.dx.org/10.22318/cscl2015.401

Chen, B., Resendes, M., Chai, C. S., \& Hong, H.-Y. (2017). Two tales of time: Uncovering the significance of sequential patterns among contribution types in knowledge-building discourse. Interactive Learning Environments, 25(2), 162175. http://dx.doi.org/10.1080/10494820.2016.1276081

Chen, B., Scardamalia, M., \& Bereiter, C. (2015). Advancing knowledge building discourse through judgments of promising ideas. International Journal of Computer-Supported Collaborative Learning, 10(4), 345-366. http://dx.doi.org/10.1007/s11412-015-9225-Z

Chuy, M., Resendes, M., Tarchi, C., Chen, B., Scardamalia, M., \& Bereiter, C. (2011). Ways of contributing to an explanationseeking dialogue in science and history. QWERTY: Interdisciplinary Journal of Technology, Culture and Education, $6(2), 242-260$.

Chuy, M., Scardamalia, M., Bereiter, C., Prinsen, F., Resendes, M., Messina, R., Hunsburger, W., Teplovs, C., \& Chow, A. (2010). Understanding the nature of science and scientific progress: A theory-building approach. Canadian Journal of Learning and Technology, 36(1). http://dx.doi.org/10.21432/T2GP4R

Cole, D., Ullman, J., Gannon, S., \& Rooney J. (2015). Critical thinking skills in the international baccalaureate's "theory of knowledge" subject: Findings from an Australian study. Australian Journal of Education, 59(3), 247-264. http://dx.doi.org/10.1177/0004944115603529

Costa, S. (2016). Math discourse in a grade 2 knowledge building classroom. Master's thesis, University of Toronto.

Fensham, P. (2008). Science education policy-making. Paris: UNESCO.

Gan, Y., Scardamalia, M., Hong, H.-Y., \& Zhang, J. (2010). Early development of graphical literacy through knowledge building. Canadian Journal of Learning and Technology, 36(1). http://dx/doi.org/10.21432/T2C01S

Hewitt, J. (2005). Toward an understanding of how threads die in asynchronous computer conferences. Journal of the Learning Sciences, 14(4), 567-589. http://dx.doi.org/10.1207/s15327809jls1404_4

Hewitt, J., \& Teplovs, C. (1999). An analysis of growth patterns in computer conferencing threads. In C. Hoadley \& J. Roschelle (Eds.), Proceedings of the 1999 Conference on Computer Support for Collaborative Learning (CSCL '99), 12-15 December 1999, Palo Alto, CA, USA (pp. 232-241). International Society of the Learning Sciences. http://dx.doi.org/10.3115/1150240.1150269

Hong, H. Y., \& Scardamalia, M. (2014). Community knowledge assessment in a knowledge building environment. Computers \& Education, 71, 279-288. http://dx.doi.org/10.1016/j.compedu.2013.09.009

Hong, H. Y., Scardamalia, M., Messina, R., \& Teo, C. L. (2015). Fostering sustained idea improvement with principlebased knowledge building analytic tools. Computers \& Education, 89, 91-102.

http://dx.doi.org/10.1016/j.compedu.2015.08.012 
Jonassen, D. H., Davidson, M., Collins, M., Campbell, J., \& Haag, B. B. (1995). Constructivism and computer-mediated communication in distance education. American Journal of Distance Education, 9(2), 7-26. http://dx.doi.org/10.1080/08923649509526885

Khanlari, A., Resendes, M., Zhu, G., \& Scardamalia, M. (2017). Productive knowledge building discourse through studentgenerated questions. In B. K. Smith, M. Borge, E. Mercier, \& K. Y. Lim (Eds.), Making a Difference: Prioritizing Equity and Access in CSCL, Proceedings of the 12th International Conference on Computer Supported Collaborative Learning (CSCL 2017), 18-22 June 2017, Philadelphia, PA, USA (Volume 2, pp. 585-588). International Society of the Learning Sciences.

Khanlari, A., Zhu, G., Costa, S., Scardamalia, M. (2018). Criss-crossing science domains in knowledge building communities: An exploratory study. In J. Kay \& R. Luckin (Eds.), Rethinking Learning in the Digital Age: Making the Learning Sciences Count, Proceedings of the 13th International Conference of the Learning Sciences (ICLS 2018), 23-27 June 2018, London, UK (Volume 3, pp. 1719-1720). International Society of the Learning Sciences.

Madden, M. E., Baxter, M., Beauchamp, H., Bouchard, K., Habermas, D., Huff, M., ... \& Plague, G. (2013). Rethinking STEM education: An interdisciplinary STEAM curriculum. Procedia Computer Science, 20, 541-546. http://dx.doi.org/10.1016/j.procs.2013.09.316

Maute, J. (1992). Cross-curricular connections. In J. H. Lounsbury (Ed.), Connecting the curriculum through interdisciplinary instruction (microfiche cards) (pp. 73-77), Columbus OH: National Middle School Association.

Mercer, N. (2007). Sociocultural discourse analysis: Analysing classroom talk as a social mode of thinking. Journal of Applied Linguistics, 1(2), 137-168. http://dx.doi.org/10.1558/jal.v1i2.137

Messina, R. (2001). Intentional learners, cooperative knowledge building, and classroom inventions. From Session 21.45 New Directions in Knowledge Building. Paper presented at the Annual Meeting of the American Educational Research Association (AERA 2001), 10-14 April 2001, Seattle, WA, USA. https://eric.ed.gov/?id=ED454178

NRC (National Research Council). (2012). A framework for K-12 science education: Practices, crosscutting concepts, and core ideas. Washington, DC: The National Academies Press.

Ofsted (Office for Standards in Education). (2010). Creative approaches that raise standards. www.creativitycultureeducation.org/wp-content/uploads/learning-creative-approaches-that-raise-standards-250.pdf

Ontario Ministry of Education. (2007). The Ontario Curriculum Grades 1-8: Science and Technology. http://www.edu.gov.on.ca/eng/curriculum/elementary/scientec18currb.pdf

Oshima, J., Oshima, R., \& Matsuzawa, Y. (2012). Knowledge building discourse explorer: A social network analysis application for knowledge building discourse. Educational Technology Research and Development, 60, 903-921. http://dx.doi.org/10.1007/s11423-012-9265-2

Piaget, J. (1964). Cognitive development in children: Piaget development and learning, part I. Journal of Research in Science Teaching, 2(3), 176-186. http://dx.doi.org/10.1002/tea.3660020306

Resendes, M. (2014). Enhancing knowledge building discourse in early primary education: Effects of formative feedback. Doctoral dissertation, University of Toronto.

Resendes, M., Scardamalia, M., Bereiter, C., Chen, B., \& Halewood, C. (2015). Group-level formative feedback and metadiscourse. International Journal of Computer-Supported Collaborative Learning, 10(3), 309-336. http://dx.doi.org/10.1007/s11412-015-9219-x

Roberts, P. (2006). Nurturing creativity in young people. London: DCMS.

Savage, J. (2010). Cross curricular teaching and learning in the secondary school. London, Routledge.

Scardamalia, M. (2002). Collective cognitive responsibility for the advancement of knowledge. In B. Smith (Ed.), Liberal education in a knowledge society (pp. 67-98). Chicago, IL: Open Court.

Scardamalia, M. (2004). CSILE/knowledge forum. In A. Kovalchick \& K. Dawson (Eds.), Education and technology: An encyclopedia (pp. 183-192). Santa Barbara, CA: ABC-CLIO. 
Scardamalia, M., \& Bereiter, C. (1991). Higher levels of agency for children in knowledge building: A challenge for the design of new knowledge media. Journal of the Learning Sciences, 1(1), 38-68.

http://dx.doi.org/10.1207/s15327809j1s0101 3

Scardamalia, M., \& Bereiter, C. (2003). Knowledge building. In J. W. Guthrie (Ed.), Encyclopedia of education (2nd ed., Vol. 17, Suppl. 3, Learning Technology Innovation in Canada, pp. 1370-1373). New York: Macmillan Reference.

Scardamalia, M., \& Bereiter, C. (2006). Knowledge building: Theory, pedagogy, and technology. In K. Sawyer (Ed.), Cambridge handbook of the learning sciences. New York: Cambridge University Press.

Scardamalia, M., \& Bereiter, C. (2016). Creating, crisscrossing, and rising above idea landscapes. In R. H. Huang, Kinshuk, \& J. K. Price (Eds.), ICT in education in global context: Comparative reports of K-12 schools innovation (pp. 3-16). Berlin: Springer-Verlag.

Scottish Government. (2008). Curriculum for Excellence. http://www.gov.scot/Publications/2008/06/06104407/5

Sternberg, R. (2003). Wisdom, intelligence and creativity synthesised. Cambridge, UK: Cambridge University Press.

Sun, Y., Zhang, J., \& Scardamalia, M. (2010). Knowledge building and vocabulary growth over two years, Grades 3 and 4. Instructional Science, 38(2), 147-171. http://dx.doi.org/10.1007/s11251-008-9082-5

Tarchi, C., Chuy, M., Donahue, Z., Stephenson, C., Messina, R., \& Scardamalia, M. (2013). Knowledge building and knowledge forum: Getting started with the pedagogy and technology. Learning Landscapes, 6(2), 385-407.

Teo, C. L. (2012). Conceptual shifts within problem spaces as a function of years of knowledge building experience. Doctoral dissertation, University of Toronto.

Tsoukas, H. (2009). A dialogical approach to the creation of new knowledge in organizations. Organization Science, 20(6), 941-957. http://dx.doi.org/10.1093/oso/9780198794547.003.0006

van Aalst, J., \& Cummings, M. (2006). Implementing knowledge building: Analysis of a face-to-face discussion by grade four students. Canadian Journal of Science, Mathematics, and Technology Education, 6, 351-368. http://dx.doi.org/10.1080/14926150609556710

van Aalst, J., Mu, J., \& Yang, Y. (2015). Formative assessment of computer-supported collaborative learning and knowledge building. In P. Reimann, S. Bull, M. Kickmeier-Rust, R. Vatrapu, \& B. Wasson (Eds.), Measuring and visualizing learning in the information-rich classroom (pp. 154-166). New York: Routledge.

Wysocky, M. (2016). Investigating how teachers effectively implement cross-curricular DPA, and identifying perceived benefits and barriers associated with crosscurricular daily physical activity. Doctoral dissertation, University of Toronto.

Zhang, J., Hong, H.-Y., Scardamalia, M., Teo, C., \& Morley, E. (2011). Sustaining knowledge building as a principle-based innovation at an elementary school. Journal of the Learning Sciences, 20(2), 262-307. http://dx.doi.org/10.2307/41305913

Zhang, J., Tao, D., Sun, Y., Chen, M. H., Peebles, B., \& Naqvi, S. (2015). Metadiscourse on collective knowledge progress to inform sustained knowledge-building discourse. Proceedings of the American Educational Research Association Annual Conference (AERA 2015), 16-20 April 2015, Chicago, IL, USA. https://tccl.arcc.albany.edu/wpsite/wpcontent/uploads/AERA15_ITMYear2_FullPaper.pdf

Zhu, G., \& Kim, M. S. (2017). A review of assessment tools of knowledge building: Towards the norm of embedded and transformative assessment. Paper presented in Knowledge Building Summer Institute (KBSI 2017), 18-22 June 2017, Philadelphia, PA.

http://ikit.org/kbsi2017/sites/kbsi2017/files/a review of assessment tools of knowledge building towards the no rm_of_embedded_and_transformative_assessment_final.pdf 